\title{
Stakeholder Network Integrated Analysis: The Specific Case of Rural Tourism in the Portuguese Peneda-Gerês National Park
}

\author{
SÓNIA NOGUEIRA and JOSÉ CARLOS PINHO* \\ School of Economics and Management, University of Minho, Braga, Portugal
}

\begin{abstract}
This study addresses the structure, nature and composition of stakeholder networks related to rural tourism in a Portuguese National Park (Peneda-Gerês National Park). In particular, it examines their interactions along the following dimensions: marketing information (marketing exchanges such as flyers, tourism information and information on specific events), administrative resources (logistic and technical support), human resources (allocation of human resources), training (training of local stakeholders in the area of promotion) and financial resources (financial support). In terms of methodology, it uses both qualitative and quantitative techniques.

The analysis of the type and nature of interactions among different stakeholders within a specific rural tourism destination is the main focus of this study. Among these, the marketing information network shows both a high number of connections and high centrality indices, which may indicate that there is a significant share of information about common projects, products and services among stakeholders. In contrast, the training network evidenced the opposite behavior pattern. The study also contributes to a better understanding of how different local stakeholders are positioned in a complex structure of interactions that are critical in providing useful directions to maximize potential opportunities that may contribute to promote rural tourism and local development efficiently. Several limitations and implications are offered in the final section. Copyright () 2014 John Wiley \& Sons, Ltd.
\end{abstract}

Received 05 June 2013; Revised 12 December 2013; Accepted 02 January 2014

KEY WORDS Social networks; relationships; stakeholders; rural tourism

\section{INTRODUCTION}

Tourism is generally viewed as a temporary short-term movement of people to destinations outside their normal environment and their activities. It is usually associated with leisure and involves at least an overnight stay (Medlik, 2003). According to Marzo-Navarro and Pedraja-Iglesias (2012), tourism activities not linked to the sun and the beach are experiencing remarkable growth. As these authors acknowledge, alternative tourist activities include those related to sports, culture, wine and adventure. In other words, alternative tourism can be defined as forms of tourism that promote sustainability and a real balance among natural, social and community values allowing both locals and tourists to enjoy positive and rewarding interactions and shared experiences (Wearing \& Neil, 1999).

Within the context of alternative forms of tourism, wildlife and ecotourism have emerged as important areas of tourism in many countries of the world (Saxena, 2005; Pavlovich, 2003). Both types of tourism try to combine aspects of both naturebased tourism and adventure travel. Transferring the discussion to the Portuguese case, tourists have a great propensity to take weekend trips motivated by leisure, gastronomy, cultural visits and drives to country side to benefit from rural tourism. (www.ipdt.pt) Rural tourism is viewed as an experience to reconnect with a past, to appreciate nature, local traditions, celebrations and art forms, a connection with what is perceived as a simpler life or a way to return to childhood (Medlik, 2003; Wanda et al., 2009). Building on this point, Schouten (1996)

* Correspondence to: José Carlos Pinho, School of Economics and Management, University of Minho, 4710-057 Braga, Portugal.

E-mail: jcpinho@eeg.uminho.pt acknowledged that this type of nostalgia basically denotes a need to escape from the stress or tedium of ordinary daily life. As Wanda et al. (2009) observed, the term rural, similar with the term of community, has been a major challenge for theorists and scholars who continue to search for its meaning.

From a theoretical perspective, the last two decades have seen an increasing number of studies on networks and networking. As Albrecht (2013, p.1) observed, 'Since the late 1990s, a growing number of authors have recognized the interconnectedness of stakeholders in the private and public sectors in tourism as well as with actors outside of these areas'. Specifically, networks enable individuals (or actors) to search for, obtain and share resources and engage in cooperative actions for mutual benefit (Saxena \& Ilbery, 2008). The context of the study is the Portuguese National Park (Peneda-Gerês National Park), which is characterized by its natural beauty and the demand for tourism. It is an International excellence PAN Park (best parks in Europe) that aims at creating and planning a system that values human activities and nature conservation. It integrates the biogenetic reserves of the Council of Europe with the 'Forest of Palheiros - Albergaria.' However, it has not been easy to manage due to the degree of complexity of different interests among various stakeholders because two countries (Portugal and Spain) are involved in its social, cultural and economic development and promotion. To promote rural tourism and local development efficiently, the coordination of the tourism network needs to involve close working interactions with diverse local stakeholders. On the basis of their core values, this will enable them to recognize the nature and type of interactions that are appropriate to reinforce at various levels (Lemmetyinen \& Go, 2009). 
This paper draws insights from two key strategic management theories: network theory and stakeholder theory. Under this approach, one way to reach a thorough understanding of stakeholder theory is to link this theory with social network analysis (SNA), which is concerned with the analysis of the structural patterns of behaviors instead of looking at the individual influences of each stakeholder (Rowley, 1997). Although the stakeholder theory is important to understand rural tourism activities, its link to social network theory within a peripheral rural location has been little explored.

The pertinence of this study lies in the fact that social networks are a relevant phenomenon that has been given increasing attention in the small business literature, in particular, regarding the rural tourism destination and local community development (Tinsley \& Lynch, 2001; Pavlovich, 2003; Gnoth, 2003; Saxena, 2005). Tinsley and Lynch (2001) researched the networking process between the destination's small tourism businesses and found the important role of cooperation between local actors. In the same line, using the principles of relationship marketing and the networks approach, Saxena (2005) examined the nature of the exchange structure in three case study locations. They analyzed different attitudes of actors toward partnership building and their perception of cross-sector networks. Araújo and Bramwell (2002) stress that partnerships and shared decision-making can be helpful for development of tourism. Under this perspective, using the network approach, Pavlovich (2003) clarifies how the grouping of small firms within interdependent systems can be self-governing and demonstrates how this process assists the destination in building tacit knowledge for competitive advantage. Cooper et al. (2009) analyzed the governance of the inter-organizational networks of key tourism stakeholders within the Gold Coast in Australia. It is relevant to emphasize that a growing number of studies using SNA have been available (Hsin-Yu Shih, 2006; Timur \& Getz, 2008; Cooper et al., 2009; Baggio et al., 2010; Leung et al., 2012; Del Chiappa \& Presenza, 2013).

On the basis of this argument, this study is two-fold: First, it aims at examining the patterns of relationships of the tourism stakeholder network in the Peneda-Gerês National Park (www.geira.pt/pnpg). Second, it analyzes the nature of interactions among different stakeholders in order to understand their impact on tourism activities, thereby promoting and planning more efficiently the rural tourism and local development. In so doing, this study deals with a gap in the literature by specifically addressing the following research questions.

(1) How are rural tourism stakeholder networks quantitatively and qualitatively composed?

(2) Who are the legitimate and powerful stakeholders for rural tourism and local development based on stakeholder theory?

(3) What are the structural positions and the nature of interactions among powerful stakeholders along a number of dimensions (marketing information, administrative and human resources, training and financial resources)?

By developing an integrated view of both network theory and stakeholder theory, this study attempts to make an incremental contribution by using SNA methodology to understand the type and nature of interactions among different stakeholders within a specific rural tourism destination. Consistent with Connelly (2007, p.108), there is increasing recognition that competitive advantage of destinations will be derived less from resources and more from 'socially constructed and socially regularized innovations'. The current study acknowledges that the structure of interactions between key stakeholders in a specific region is an important driver to improve communication and decision-making (Cooper et al., 2009). Among these interactions, special focus is given to marketing information, administrative and human resources, training and financial resources. Morrison et al. (2004) reported that some of the success factors associated with tourism networks are related to the establishment of a culture of trust but also to the sharing of resources (such as marketing, administrative, human, training and financial resources). Whereas marketing information considers all the exchanges related to events, promotion, tourism information and projects, administrative and technical resource exchanges include those capabilities related to effectively managing the bureaucracy, documentation, archiving and dissemination of data. In turn, human resource exchanges include transfer of staff between organizations. Finally, whereas training includes transfer and acquisition of knowledge and know-how, financial resources encompass the set of monetary resources available.

Results have shown that the marketing information interactions (or network) are seen to be the most important among local stakeholders, which suggests that this resource or attribute has a strategic significance in the overall structure of the network. The density of this network also shows that two major stakeholders (ADERE-PG and DGAC-North) cooperate intensively in promoting the Wild National Park tourism activities. The remainder of the paper is organized as follows: we review the major theories of study, namely, stakeholder theory and network theory. After this, we present the study methodology, focusing on the data collection procedure. Subsequently, the findings of this study are discussed. Finally, the conclusions, implications and future research directions are presented.

\section{LITERATURE REVIEW}

\section{Stakeholder theory}

There is some consensus in the literature (Rowley, 1997; Timur, 2005; Lewis, 2006) about the origin of the concept of stakeholder, which can be traced back to the early 1960s where it was first mentioned in a Stanford Research Institute Memo (Freeman, 1984). The publication of Freeman's work, in 1984, is the cornerstone for the development of stakeholder theory, which would be further used in management, marketing and, more recently, tourism (Lewis, 2006). The concept of stakeholder varies over time and from author to author. To Freeman (1984), stakeholders, in an organizational and management context, are any groups or individuals who can affect or are affected by the achievement of organizational goals. The concept is underpinned by the idea of two types of stakeholders: strategic and moral. Zsolnai (2006) proposes a 
reinterpretation of the concept of stakeholder, stating that not all stakeholders are morally valid and only those who are should be considered. In the same line, Attas (2004) refers to whoever has something to lose, in financial, social or psychological terms, with the fall of the company.

Over the past thirty years, stakeholder theory has been used in multiple contexts, namely, assessment of performance (Keeley, 1978), development of competitive advantages (Slatter, 1980) and development of the company mission (Pearce, 1982). In terms of planning and management in tourism, emphasis should be given to the role and the importance of a vast number of studies that used stakeholder theory as a management tool for business ethics, longitudinal analysis of stakeholders' attitudes (see, for instance, Sautter \& Leisen, 1999; Yuksel et al., 1999; Robson \& Robson, 1996; Timur, 2005; Ioannides, 2001) ethics in tourism marketing, identification of stakeholders and perceptions related to sustainable tourism (Hardy \& Beeton, 2001; Timur, 2005). For their part, Mitchell et al. (1997) conducted a review of stakeholder theory proposed first by Freeman (1984) and identified both power (also emphasized by Frooman, 1999) and legitimacy as the core attributes of a stakeholder's typology. Urgency was also added, and therefore, the model of stakeholder salience was proposed. This model can be defined as 'the degree to which managers give priority to competing stakeholder claims' (Mitchell et al., 1997, 584). Driscoll and Starik (2004) criticized this model and extended it re-conceptualizing the attributes of power, legitimacy and urgency. They also proposed a fourth attribute, proximity, which is the 'state, quality or fact of being near or next' (Driscoll and Starik, 2004:63).

Robson and Robson (1996) highlight the need for more integration between stakeholders and tourism planning in order to balance tourism, social and environmental interests. From a destination perspective, stakeholders are viewed as individuals, groups or organizations with an interest in a specific area or domain (Wood \& Gray, 1991; Cooper et al., 2009). Murphy and Murphy (2004) established four types of tourism stakeholders: consumers, businesses operating in tourism, residents and governing bodies. In terms of planning and management in tourism, it is worth mentioning the following studies: Sautter and Leisen (1999), Yuksel et al. (1999), Getz and Jamal (1994) and Robson and Robson (1996), who applied the theory of stakeholders as a management tool for tourism activities. Other studies stand out in the longitudinal analysis of the attitudes of stakeholders (Ionnides, 2001), the application of stakeholder theory as an ethical tool in tourism marketing, the development of a tourism plan (Pforr, 2002) and the identification of the main stakeholders and their perceptions in relation to sustainable tourism (Sheehan \& Ritchie, 1997; Hardy \& Beeton, 2001; Timur, 2005).

\section{Social network theory}

Social network theory (SNA) views organizations as systems of people, groups and businesses linked by multiple relations (Tichy et al., 1979; Serrat, 2009) where shared values, visions, ideas, social contacts, financial or commercial exchanges occur (Serrat, 2009). According to Scott et al. (2008), there are specific sets of relationships (ties) that link groups of people, objects and events. According to Scott (2000), SNA has its origin in three research streams: (i) the socio-metric perspective (that used and developed the graph theory); (ii) the Harvard perspective, which pioneered the use of inter-relational models and cliques and, after 1970, developed the algebraic models; and (iii) the anthropologist perspective of the Manchester School, which focused on the analysis of structural relations of power/conflict. A later work by Scott et al. (2008) categorized the evolution of networks in two schools: one based on mathematics and another based on the study of social sciences, both with relevance in the mid-twentieth century. Wasserman and Faust (1994, p.4) acknowledged 'the social network perspective encompasses theories, models, and applications that are expressed in terms of relational concepts or processes. That is, relations defined by linkages among units are a fundamental component of network theories'.

There are a wide range of topics in social sciences that employ methods of SNA. From a marketing and strategy perspective, SNA has been increasingly applied in the analysis of distribution channels in marketing (Iacobucci \& Hopkins, 1992), in understanding consumer behavior (Wasserman \& Faust, 1994, Rowley, 1997), in word-of-mouth communication (Duhan et al., 1997) and in relationship marketing (Iacobucci \& Ostrom, 1996).

As Halme (2001) acknowledged, in the tourism sector, small businesses with limited budgets, which are not able to make sustained development, are often found operating alone. One specific characteristic of the tourism sector lies in its geographical fragmentation, sometimes in remote areas, far from huge market populations and composed of small independent companies with high staff turnover (Scott et al., 2008).

In line with Morrison et al. (2004), some of the success factors associated with tourism networks relate to the establishment of a culture of trust, interdependence, reciprocity, resource sharing and interconnection between the community network members. It should be emphasized the study undertaken by Tinsley and Lynch (2001) who examined informal tourism-related networking in a rural destination. They included in their analyses a number of various tourism players, such as hotels, bed and breakfasts, gift shop, art, grocery stores and craft shops, and found the important role of cooperation among these actors. Another interesting research stream has been focused on the destination development view (Pforr, 2006; Pavlovich, 2003). For instance, Pavlovich (2003) studied how the relationships between organizations can act as a self-organizing mechanism for the destination, with fluidity and change being a critical factor in this process. The establishment of network studies had led to insights into the structure and organization of networks within or involving players from tourism industries (Albrecht, 2013). SNA was employed to illustrate these dynamics and show the structural morphology based on indicators of density and centrality into the tourism research (Baggio et al., 2010; Leung et al., 2012; Hsin-Yu Shih, 2006). Hsin-Yu Shih (2006), for instance, examined the networks characteristics of tourism destinations. Specifically, she analyzed the structural configuration of each destination within a particular area by using a number of indicators from SNA. Using an 
SNA approach, Leung et al. (2012) examined both the tourism attractions visited by overseas tourists and the changes in the pre-Beijing Olympic Games, during Beijing Olympic Games and post-Beijing Olympic Games and the overseas tourist movement patterns.

\section{INTEGRATING STAKEHOLDER AND NETWORK THEORY IN TOURISM DESTINATION}

Although the major concern of the stakeholder theory is the identification and classification of different stakeholders, its integration with the network theory provides a strong basis 'for identifying critical stakeholders in destination development' and to determine 'whether identified critical stakeholders have existing relationships with the other members of destination frameworks' (Timur \& Getz, 2008, 446). Also, Rowley (1997) and Kimbu and Ngoasong (2013) take this view forward by examining the multiple stakeholder interdependent relationships.

The stakeholder perspective and the network theory have been used in the context of tourism (examples: Stokowski, 1992; Borgatti \& Foster, 2003; Timur \& Getz, 2008; Scott et al., 2008; Cooper et al., 2009; Kimbu \& Ngoasong, 2013). The literature has given rise to strong debate between the paradigm of inter-organizational networks (Borgatti \& Foster, 2003; Podolny \& Page, 1998) and research networks, which emphasize traditional qualitative methods. Consistent with Timur (2005), it is important to consider the need to integrate topics related to tourism with relational network analysis in order to understand the nature of flows between different stakeholders operating in this particular field. This challenges the idea that small tourism players operate as isolate actors. In fact, as observed by several authors, more than ever, the capacity to cooperate effectively with other stakeholders is becoming a core capability of any organization. This is particularly relevant for small firms whose skills and resources lie often outside their own boundaries. This point was stressed by Morrison and Thomas (1999) who acknowledged that small businesses are typically associated with a shortage of funds and evidence a lack of management and marketing skills.

According to O'Donnell et al. (2001), the analysis of the content of network relationships is associated with inter-connections and ties framed within a specific structure that contributes for small tourism business to overcome shortage of resources and competencies. Hence, firm's networking with relevant stakeholders is crucial to revitalize their resources, structures and processes. Within regional strategies, Grabher (2006) viewed networking as a governance model that originated in the notion of embeddedness. As he acknowledged, the governance of networks comprises a broad spectrum from authoritative to distributed forms of hierarchy. However, it should be emphasized that small tourism firms lack market power for negotiation, and formal hierarchy may be incompatible toward the advantage of simple organizational structures and processes (Laere van \& Heene, 2003). In these types of firms, the entrepreneur assumes particular relevance.
For his part, Rowley (1997, p.890) observed that 'firms do not simply respond to each stakeholder individually; they respond, rather, to the interactions of multiple influences from the entire stakeholders set. Thus, explanations of how organizations respond to their stakeholders requires an analysis of the complex array of multiple and interdependent relationships existing in stakeholder environments'.

\section{RESEARCH METHODOLOGY AND DATA COLLECTION}

The intended research methodology builds heavily on qualitative and quantitative methods such as case studies and SNA. A review of the relevant literature reveals that the most commonly used methodology is the case study in the context of network analysis, as it generates relevant and rich information about the social dynamics and the operations developed over time (Coviello, 2005). However, despite its relevance, the number and diversity of relevant actors in the network makes this methodological approach sometimes difficult to implement. Relevant actors mean those informants that are likely to be strongly involved in the strategic decisions of their organizations, particularly related to rural tourism decisions. To ensure that the respondents were sufficiently knowledgeable to provide the required information accurately, we followed a snowball sample. Networks are always embedded in specific locations, although the extent of their geographical reach and complexity may vary (Saxena \& Ilbery, 2008). As these authors note, 'embeddedness suggest not only that resources or activities are directly linked to place but also that relationships are formed within particular sociocultural contexts in specific localities' (Saxena \& Ilbery, 2008, p. 237). Given the reality under analysis, this research adopts a three-stage research design.

Stage one: A list of key stakeholders involved in the Peneda-Gerês National Park rural tourism activities was identified and developed on the basis of secondary data (blogs, websites, brochures, books, marketing data, etc.). This is in line with Cooper et al. (2009), who observed that identification of the relevant class of stakeholders is important for destination managers to achieve their organizational objectives. Therefore, this preliminary analysis enabled us to produce an initial list of relevant stakeholders (based on Mitchell et al., 1997, 'stakeholder salience' model) involved in Peneda-Gerês National Park rural tourism and local destination.

Stage two: Exploratory field work based on exploratory interviews (recorded, transcribed and analyzed) was undertaken in order to identify and confirm key players in the Peneda-Gerês National Park rural tourism. This option was justified by the need to define the network boundaries in order to facilitate the analysis of relationships within the network of stakeholders involved in implementing tourist activities. These exploratory interviews allowed us to define a final validated list of key stakeholders to be considered for the study. This qualitative technique is well known in the literature as it makes possible to define network boundaries, particularly when faced with a large number of actors. At this stage, a list of stakeholders was produced and 
assessed, and the different stakeholders were ranked on the basis of the theory by Mitchell et al. (1997) and further revised by Driscoll and Starik (2004). To better understand, Mitchell et al. (1997) proposed a model for identification of relevant stakeholders (stakeholder salience), which considers that stakeholders that have three main attributes (power, legitimacy and urgency) are more relevant than others. On the basis of these three main criteria Mitchell et al. (1997) categorize stakeholders in six categories, namely,

(1) dormant stakeholders - have power but do not have a legitimate relationship, so their power becomes useless;

(2) discretionary stakeholders - have a legitimate relationship but no power, so do not influence the organization;

(3) demanding stakeholders - have power and legitimacy, so their influence on the organization is assured;

(4) dangerous stakeholders - have urgency and power, so they tend to be coercive and even potentially violent;

(5) dependent stakeholders - have urgency and legitimacy but lack of power, so soon become dependent on others to carry out their intentions; and

(6) final (definitive) stakeholders - have power, legitimacy and urgency, so become priority and relevant stakeholders.

The results allowed us to validate the initial list of stakeholders considered for the purposes of the study. The major criteria used for selecting the major key players were power, legitimacy, urgency and proximity (Mitchell et al., 1997). Additionally, a first in-depth interview was developed with ADERE-PG, a key public entity actor that is responsible for managing Peneda-Gerês National Park activities.

Stage three: This involved the personal application of the questionnaire administered to 46 relevant stakeholders in the Peneda-Gerês National Park. This stage enabled the collection of relevant information about the structure of relationships in the Peneda-Gerês National Park tourism network, the type and nature of relationships among actors and the major responsible for implementing rural tourism projects. The questionnaire was pre-tested with three academics and with one of the main representatives of the ADERE-PG. On the basis of these initial interviews, 46 key stakeholders were identified, and each organization was interviewed in person with the interviews taking around forty minutes.

Concerning the data collection procedure, performing an SNA usually requires collection of data from all members of a population or the use of representative samples of the population. For the present study, although a snowball sample was adopted, the sampling frame includes $46(n=46)$ key stakeholders operating in the specific region known as Peneda-Gerês National Park. Although the study may be seen to use a small sample, the respondents were perceived as the key stakeholders in the region. The unit of analysis was considered the interactions between these key stakeholders. It should be noted that this study adopted the methodologies inherent to SNA and measures of network analysis such as network size, symmetry, density, intensity and centrality (see, for instance, Timur, 2005; Timur \& Getz, 2008; Hsin-Yu Shih, 2006; Leung et al., 2012).

\section{FINDINGS AND RESULTS}

Considering the major objectives of this study, it was necessary to do the following: (i) list the relevant stakeholders operating in the Peneda-Gerês National Park rural tourism and (ii) design a graphical representation of the different types of flows (marketing information, administrative resources, human resources, training and financial resources) between the various stakeholder groups. Whereas the qualitative stage of this study allowed the identification of relevant stakeholders (involved in the decisions of Peneda-Gerês National Park tourism), the quantitative stage enabled the identification of different flows (interactions) among different stakeholders.

Concerning the first objective, this study follows Frooman's (1999) study, which identified and classified different stakeholders under the model of stakeholder salience, also proposed by Mitchell et al. (1997). Therefore, three categories were considered:

(1) discretionary stakeholders - Association for the Development (local actors: Fafião; Gerês Living Tourism Association, PNPG with People, Social and Cultural Association of Paredes de Rio), have legitimacy but have no power;

(2) dependent stakeholders (Peneda-Gerês National Park entrance) - have legitimacy and urgency but depend on others to support them; and

(3) final stakeholders (remaining 37 stakeholders) - represent a group that has power, legitimacy and urgency and were named as priority stakeholders.

Among the final stakeholders, DGAC-North (public entity) was the one that showed most power, legitimacy and urgency, followed by the five city councils and lastly by the ADERE-PG (local public entity). From this data, it was possible to confirm the findings of Pesqueux and Damak-Ayadi (2005) who argued that, within the stakeholder framework, the organization has relationships with various groups that affect or are affected by their decisions. As outlined by Frooman (1999), the most relevant stakeholders control those types of resources that are critical to the business (information, human and financial resources). Subsequently, network analysis was used to build a network structure that depicts different interactions among different actors.

A list of the most representative stakeholders was presented to respondents who were asked to identify those with which their organization had joint programs or projects in the last twelve months (Timur \& Getz, 2008). Then, relying on their responses to this question, an 'adjacency matrix' was built to represent each interaction (marketing information, administrative resources, human resources, training and financial resources). A ' 1 ' stands for the presence of a specific interaction between stakeholder $i$ and stakeholder $j$, and ' 0 ' indicates a lack of interaction.

The marketing information network shows the centrality of ADERE-PG and DGAC-North. The degree of centrality of actor $i$ is the number of ties divided by the number of possible ties $C i=d i /(g-1)$ whereas the network centralization is given by $\left.C=S U M^{g}{ }_{i=1}(\max (C i)-C i) / g-2\right)$. 
As central actors, these stakeholders have central access to information and a relevant positioning in the network, such as easy access to other actors, more power and more legitimacy.

The global social network examined has a $51.2 \%$ index of reciprocity (number of bidirectional relationships). This means that out of the 263 existing relationships, 134 are bidirectional (both from one actor to another).

The density (network structure) represents the number of links in relation to the number of possible connections. Network density is the measure most commonly used (to make it possible) to ascertain the extent to which all actors are connected. The formula for calculating the density is $m /[n(n$ $1)$ ] where $m$ is the number of existing connections and $n$ is the number of players (Scott, 2007). Concerning the global stakeholders network involved in tourism projects in PNPG, we have the following calculation for the density: $D=263$ / $(46 \times 45)=12.7 \%$. Therefore, the higher the density of actors' contacts, the more likely resources recirculate within the network structure. Figure 1 presents a graph illustrating the marketing information exchange network (node size indicates the degree of the actors).

The marketing information networks present 265 links and $12.7 \%$ density $(0,127)$. The reciprocity level is $48.88 \%$, indegree is $59.61 \%$ and outdegree is $61.88 \%$. Thus, we may conclude that the marketing information exchange network presents a considerable number of connections and high centrality indices. ADERE-PG has the highest degree, followed by DGAC-North. ARDAL and the City Council of Arcos de Valdevez and Melgaço have a relatively high degree after ADERE-PG and DGAC-North, which is not the case with the three other city councils involved (Ponte da Barca, Montalegre and Terras de Bouro) (local actors). Specifically, this result suggests that there is a close cooperation among different actors with regard to share of market information about potential customers and activities promoting tourism within the park. With regard to the administrative resources, Figure 2 presents a graph illustrating the administrative exchange network (node size indicates the degree of the actors).

The administrative network has 73 links and a low density of $3.53 \%(0,035)$. The index of reciprocity is low $(32.73 \%)$, as in this context, there are mainly unidirectional flows. The indegree is $23.65 \%$ and the outdegree is $28.20 \%$. Thus, it is concluded that in the context of administrative resources, we have a sparse network with few bidirectional ties. ADERE-PG has the highest degree, followed by DGACNorth. The city council of Montalegre comes after ADERE-PG and DGAC-North, which is not the case with the other city councils involved (Ponte da Barca, Arcos de Valdevez, Terras de Bouro and Melgaço). Figure 3 presents a graph illustrating the human resource network (node size indicates the degree of importance of the actors).

The human resources network reveals 64 links and a low density of $3.09 \%(0,030)$. The reciprocity index is low and accounts for $28 \%$ (e.g. in this context, there are mainly unidirectional flows). The indegree is $17.28 \%$ and the outdegree is $24.09 \%$. Thus, we may conclude that the human resources network has a sparse network with few bidirectional relationships. ADERE-PG has the highest degree, followed by

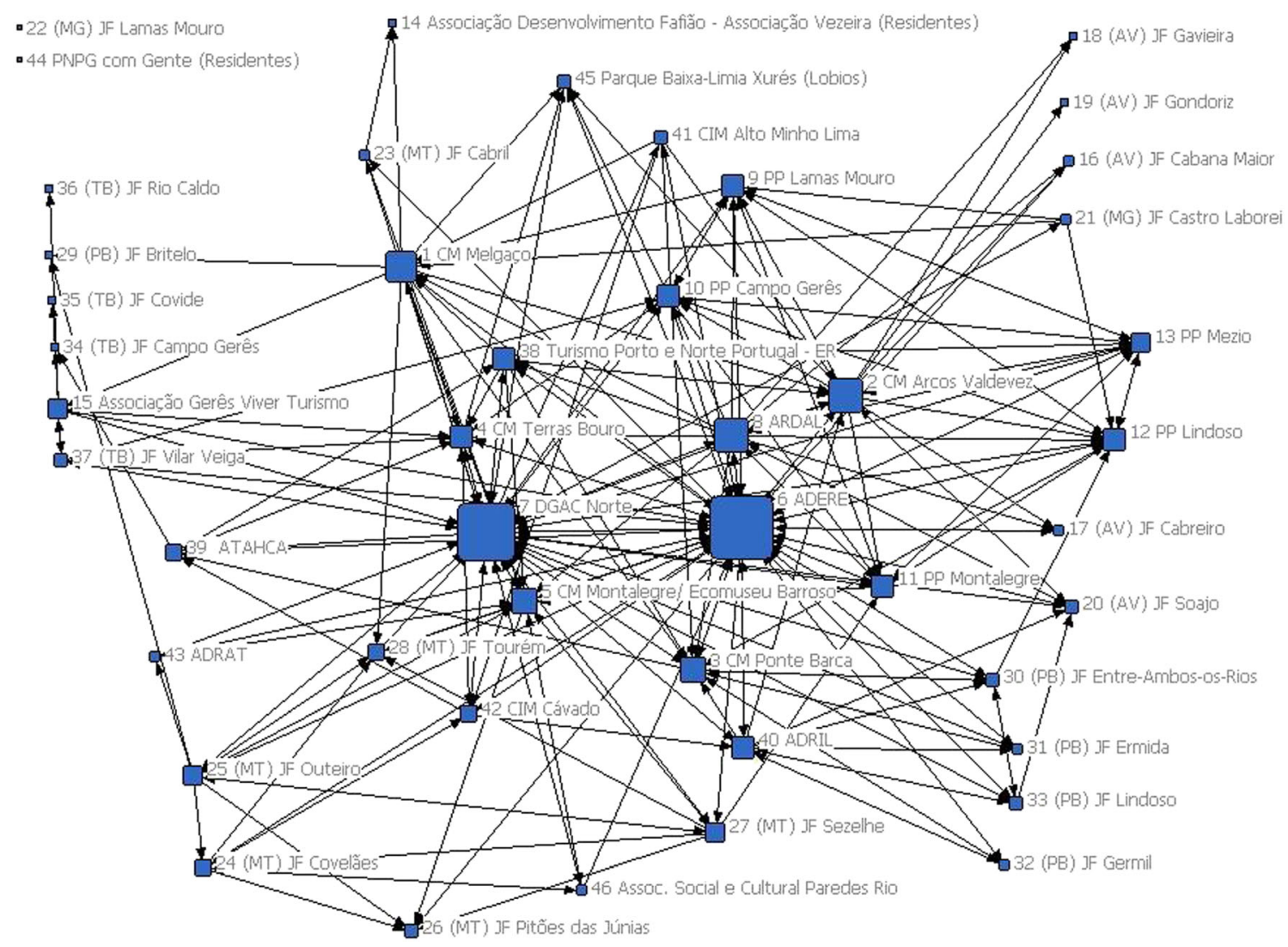

Figure 1. Marketing information network. This figure is available in color online at wileyonlinelibrary.com/journal/jtr 
- 15 Associação Gerês Viver Turismo

- 16 (AV) JF Cabana Maior

- 17 (AV) JF Cabreiro

- 18 (AV) JF Gavieira

- 19 (BV) JF Gondoriz

- 22 (MG) JF Lamas Mouro

- 25 (MT) JF Quteiro

- 29 (PB) JF Britelo

- 30 (PB) JF Entre-Ámbos-0s-Rios

- 31 (PB) JF Ermida

- 32 (PB) JF Germil

- 33 (PB) JF Lindoso

- 34 (TB) JF Campo Gerês

- 35 (TB) JF Covide

- 36 (TB) JF Rio Caldo

- 39 ATAHCA

- 44 PNPG com Gente (Residentes

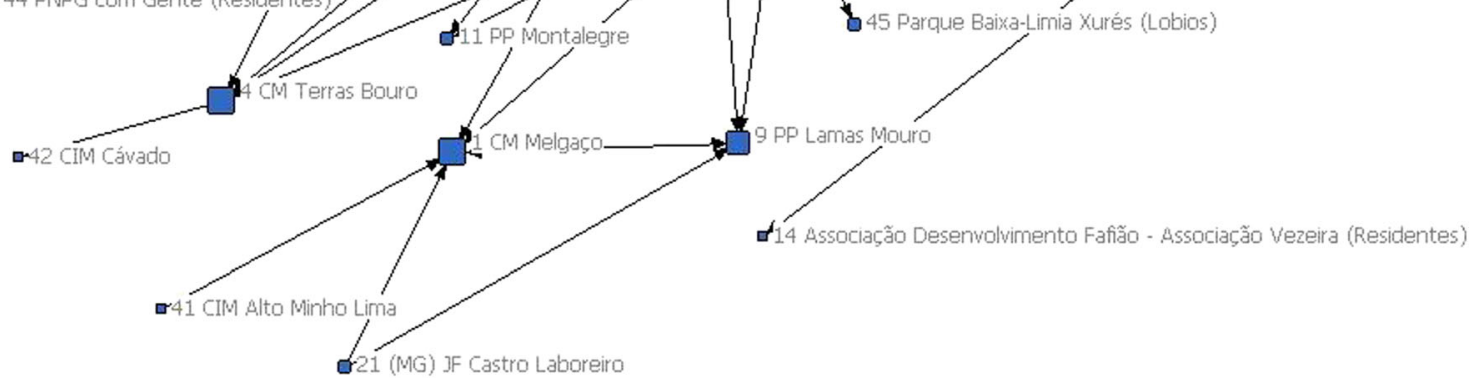

Figure 2. Administrative network. This figure is available in color online at wileyonlinelibrary.com/journal/jtr

- 15 Associação Gerês Viver Turismo

- 16 (AV) JF Cabana Maior

- 17 (B.V) JF Cabreiro

- 18 (AV) JF Gavieira

- 19 (BV) JF Gondoriz

- 25 (MT) JF Outeiro

- 26 (MT) JF Pitỗes das Júnias

- 29 (PB) JF Britelo

- 30 (PB) JF Entre-Ambos-os-Rios

- 31 (PB) JF Ermida

- 32 (PB) JF Germil

- 33 (PB) JF Lindoso

- 34 (TB) JF Campo Gerês

- 35 (TB) JF Covide

- 36 (TB) JF Rio Caldo

- 39 ATAHCA

- 43 B.DRBT

- 44 PNPG com Gente (Residentes)
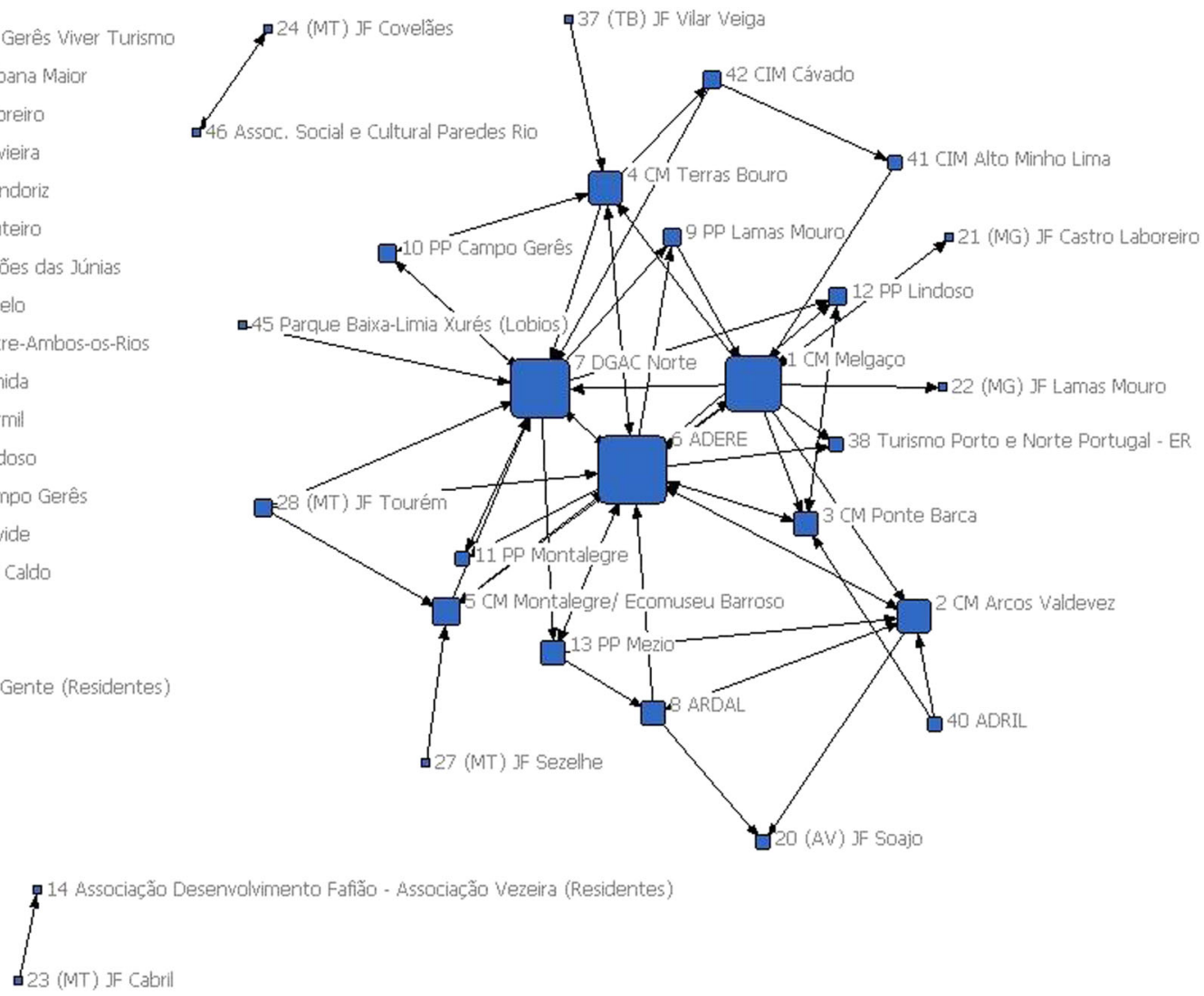

Figure 3. Human resources network. This figure is available in color online at wileyonlinelibrary.com/journal/jtr 
DGAC-North and the city council of Melgaço. Figure 4 presents a graph illustrating the training network (node size indicates the degree of importance of the actors).

The training network has 47 links and a density of $2.27 \%$ $(0,227)$. The reciprocity index is $14.6 \%$, the indegree is $18.43 \%$ and the outdegree is $14.46 \%$. Thus, we may conclude that this network is not very dense, has few connections and has reduced reciprocity. ADERE-PG has the highest degree, followed by DGAC-North and the city council of Melgaço. The graph illustrating the financial resources network is presented in Figure 5 (node size indicates the degree of importance of the actors).

The financial resources network has 80 links and a low density of $3.86 \%(0,038)$. The reciprocity index is low $(19.40 \%)$ as in this context, there are mainly unidirectional flows; the indegree is $25.58 \%$ and the outdegree is $16.49 \%$. Thus, we may conclude that in the case of the financial resources, the network is sparse, with few connections. ADERE-PG has the highest degree, followed by DGAC-North and ADRIL.

Regarding the exchanges established inside the analyzed network and considering them from the highest to the lowest number of connections, the following sequence is presented: (i) marketing information; (ii) exchange of financial resources; (iii) administrative resources; (iv) human resources; and (v) training. The degrees of density and centrality follow the same pattern; i.e., the marketing information network presents the highest density $(0,127)$, the highest input indegree centrality $(59.61 \%)$ and the highest output outdegree (61.88\%). By contrast, the training network presents the lowest density ( 0 , $227)$, the lowest reciprocity $(14.6 \%)$ and the lowest output degree (14.46).
The previous analysis allows us to identify key interactions as critical success factors upon which networks rely upon to bring about coordination and efficient cooperation among different stakeholders (Morrison et al., 2004). Additionally, managing the complexity of the interactions between different actors is essential for effective communication and for reducing potential barriers to cooperation, maximizing the success of potential future common projects. The development of tourism projects does not require separate products but rather a common strategy and joint efforts in order to achieve collective results. The results indicate the importance of involving and combining several key actors in the process of development of tourism activities in the Peneda-Gerês National Park.

In order to detail the analysis and given the nature of variables involved, several Spearman's rho correlations were computed to analyze the most important correlations among several dimensions. For instance, the study showed a positive and statistically significant correlation between the type (and nature) of flows within the existing networks and several factors chosen by stakeholders (i.e. geographical proximity, personal affinities and contacts, etc.) within the same network. It is worth mentioning the importance of information and marketing networks and also the administrative and the human resource networks (Figures 1, 2 and 3). Results showed a positive correlation between the following: information marketing exchanges and both personal affinities $(r=0.35 ; p<0.05)$ and personal stakeholder contacts $(r=0.33 ; p<0.05)$. Similarly, a positive correlation was found between human resource exchanges and geographic proximity $(r=0.49 ; p<0.05)$ and between administrative exchanges and geographical proximity $(r=0.43 ; p<0.05)$. These results reinforce the

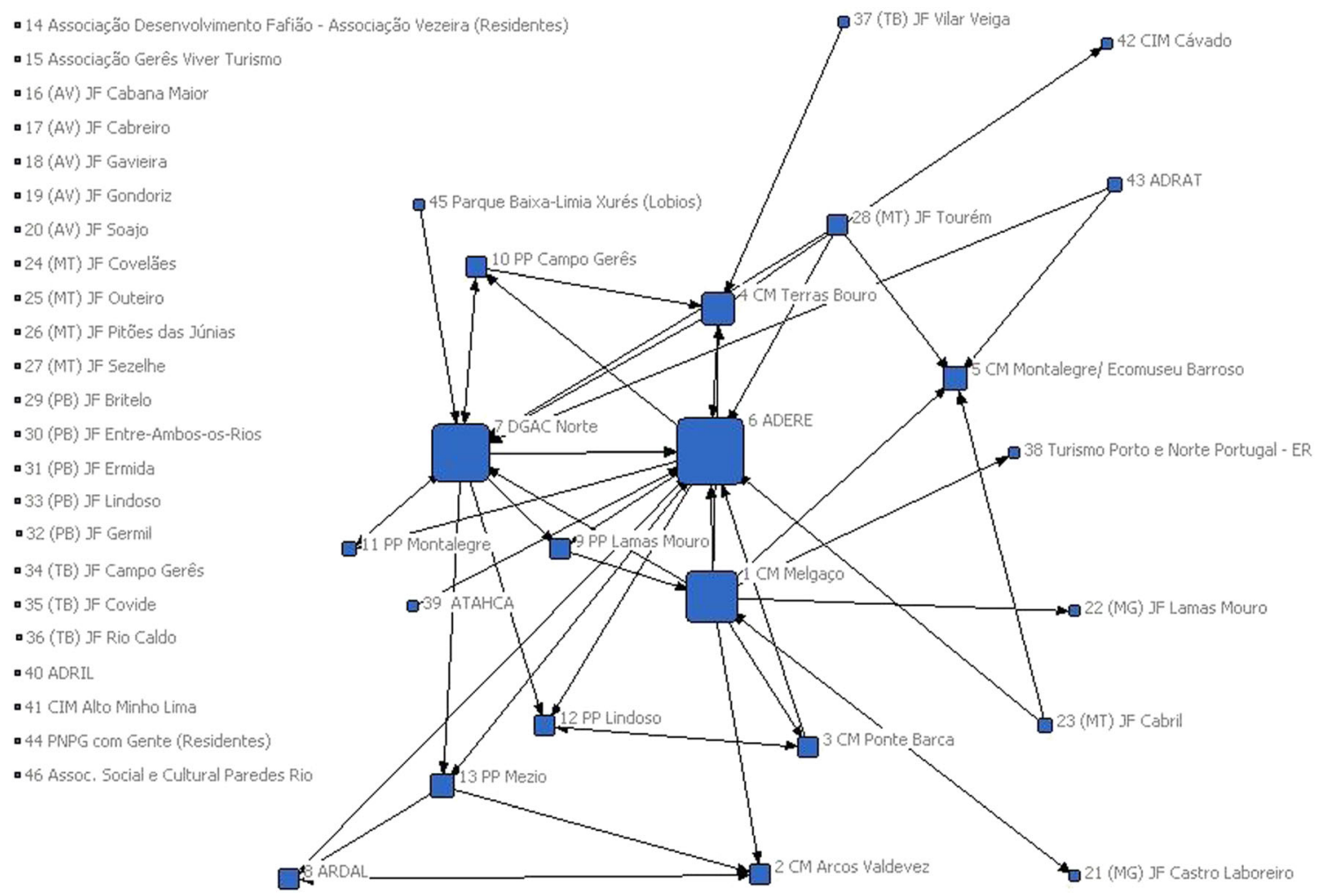

Figure 4. Training network. This figure is available in color online at wileyonlinelibrary.com/journal/jtr 


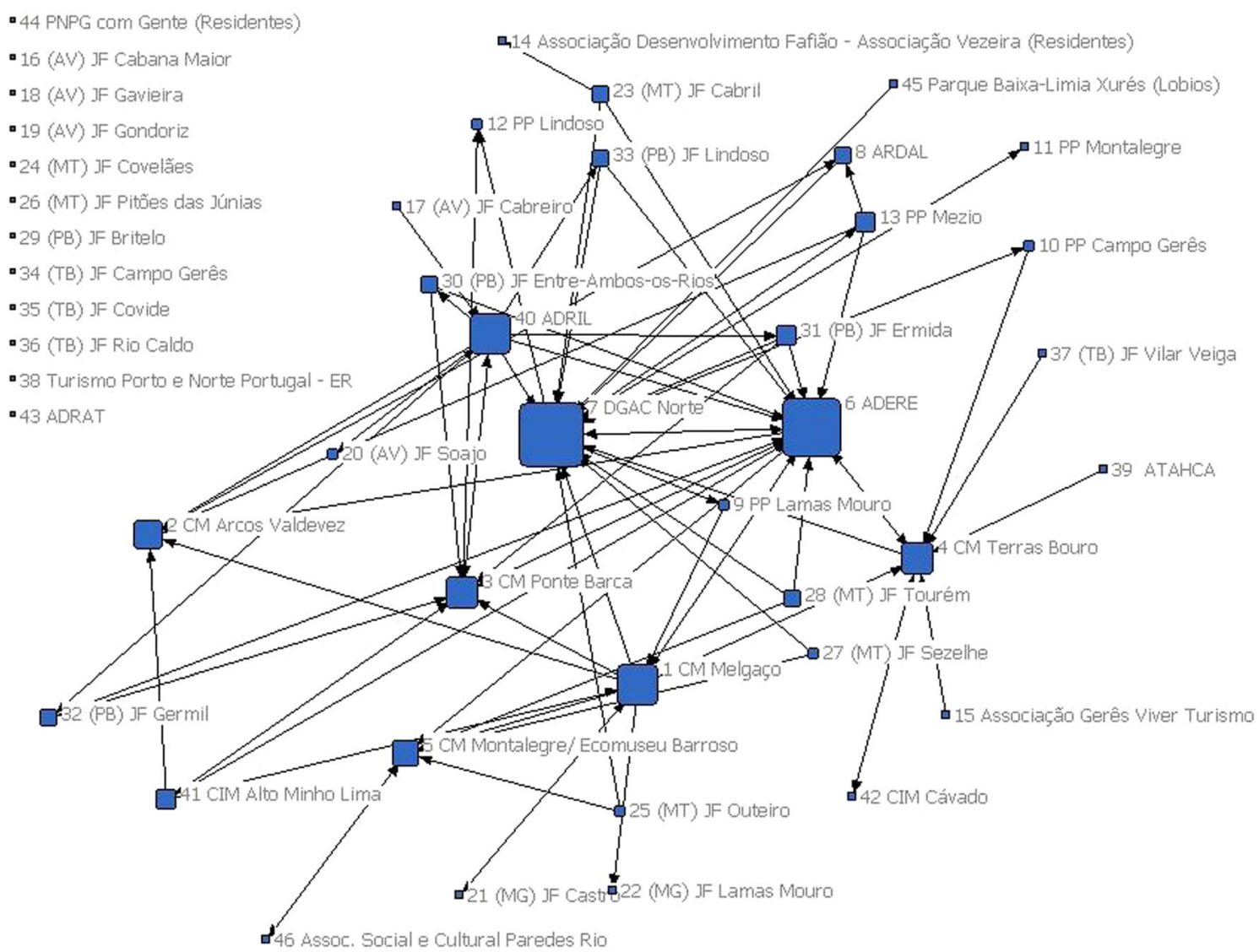

Figure 5. Financial resources network. This figure is available in color online at wileyonlinelibrary.com/journal/jtr

recommendation proposed by Driscoll and Starik (2004), who proposed an extension of the model by Mitchell et al. (1997) by including the proximity dimension.

The most valued factor in choosing a partner network is the network of contacts that the stakeholder possesses. When analyzing the goals and interests of various stakeholders, the study makes possible to identify the stakeholders more centered on the growth of the tourism sector of Peneda-Gerês National Park. Concerning the structural positioning of different actors, the ADERE-PG emerges as a central actor in the network, in terms of outdegree centrality (32) and indegree centrality (number of interactions received from is 30). It is also the actor that reveals the greatest ability to articulate and manage all interactions among actors. The outdegree centrality reveals the number of relationships that starts from the actor, whereas the indegree centrality refers to the number of interactions received by the actor (Wasserman \& Faust, 1994; Scott, 2007).

This actor (ADERE-PG) proves to be more central than the DGAC-North (the direction of Peneda-Gerês National Park). Thus, ADERE-PG shows itself to be a relevant partner for all actors due to its privileged position in the network, enabling high intermediation with a vast number of connections who do not have direct contact.

DGAC-North also reveals an indegree centrality of $62 \%$ and an outdegree centrality of $62 \%$. The Mezio entrance gates (a local tourism infrastructure for tourism information) lie between the five different Peneda-Gerês entrance gates (Mezio, Lamas de Mouro, Campo do Gerês, Lindoso and
Montalegre) and display an outdegree centrality of $20 \%$. On the other hand, the entrance gates of Campo do Gerês and Lamas de Mouro show an indegree centrality of $20 \%$. It should be noted that there are some actors with null outdegree such as: Rio Caldo parish council, Vezeira Association, Britelo parish council, Campo do Gerês parish council, CIM Cávado, Gavieira parish council, PNPG with People, Lamas de Mouro parish council and Covide parish council. These actors are the ones who have the least capacity to articulate the network since they have the lowest sum of indegree and outdegree.

Results indicate that marketing information about common projects, products and services results in relational value for different stakeholders involved. Basically, rural tourism networks could be viewed as a market in which nodes are connected by service providers who add value by contributing their specific core competencies (Lemmetyinen \& Go, 2009).

Without claiming to be exhaustive, a summary of the main results will be presented involving a qualitative analysis. One important finding relates to the fact that most interviewees shared a common idea of offering a memorable and unique experience to tourists while preserving the natural beauty of the region.

Another issue relates to the importance of the relationship quality among different stakeholders. This component is reflected in dimensions such as trust, cooperation and commitment, which are critical for stakeholder involvement in the Peneda-Gerês National Park (PGNP) rural tourism activities. According to several interviewees, this involvement may occur particularly 
with regard to the planning process contributing to the promotion and development of the PGNP. A deep involvement of different stakeholders in different activities provides numerous benefits for the whole community. To achieve this objective, providing information and training to local residents concerning different rural tourism activities should help them to take full advantage of the benefits. Ultimately, local residents need to be part of tourism experiences through provision of knowledge, services, facilities and local products.

\section{DISCUSSION AND CONCLUSION}

It is generally accepted that tourism relies on a range of physical, ecological, social and cultural resources, and when it is unplanned and not efficiently managed, it can seriously damage the resource base and the image of a specific destination (Timur, 2005).

The small size of organizations involved in Peneda-Gerês National Park rural tourism activities and the need to build a common strategy specific to rural regions, such as the case under study, are possible if we understand who the major stakeholders operating in the field are (public organizations, private organizations, local community, etc.) and the nature of their interactions (marketing information, administrative resources, human resources, training and financial resources). This makes possible to promote cooperation and to develop more efficient communication, cohesiveness, knowledge and innovation (Cooper et al., 2009). The reason why Peneda-Gerês National Park rural tourism was chosen is because it is the only national park in Portugal and one of the few European (or international) Pan Parks characterized by its biodiversity, beauty, rich gastronomy and also cultural and historical factors, which make it an excellent tourism destination. This approach relies mainly on a destination perspective that is in line with that taken by Cottrell and Cutumisu (2006) who focused on sustainable tourism strategies in the World Wide Fund for Nature Pan Parks. Their strategy mainly focused on regional and local stakeholders.

By applying SNA methodology, this study provides numerous techniques and indicators which evidenced the structural patterns among different stakeholders including host communities, operators, tourists and managers as well as a whole range of other entities, such as nonprofit organizations, small businesses and local government entities. Dealing with this diversity of stakeholders with a wide range of interests and objectives is not an easy task. Relying on the model by Mitchell et al. (1997), this study identified powerful stakeholders employing three main attributes: power, legitimacy and urgency. It also presented an integrated perspective by considering the type of stakeholders involved, their interests and goals and their relationship concerning marketing information, administrative and human resources, training and financial resources.

Concerning the marketing information network, which in the context of this study means sharing relevant information about common projects, products and services, it presents a high number of connections (265 links) reflected in high centrality indices. This means that this resource (or attribute) has a strategic significance on the overall structure of the network. The density of this network also shows that relevant stakeholders work closely together as a team. In line with Timur and Getz (2008), stakeholders with more attributes are seen as being more powerful and influential as a consequence of their functional roles within the tourism network. This is the case of both important stakeholders ADERE-PG and DGAC-North (local public entities). Surprisingly, residents in the Peneda-Gerês National Park have a marginal positioning within the network. This seems to be a major constraint to most structural social networks since the involvement of local residents not only benefits the local community and the environment but also improves the quality of the tourist experience. The coordination of the tourism network needs to involve close working interactions with local people. On the basis of their core values, this will enable them to recognize what types of interactions are appropriate at various levels (Lemmetyinen \& Go, 2009).

In contrast to the marketing information network, the training network shows low centrality indices evidencing low connection (47 links) among different stakeholders. The low connection and density of this network structure may indicate that more work needs to be done in terms of training. In fact, it is crucial for different stakeholders to be more involved in Peneda-Gerês National Park activities, particularly in providing information and training for residents about different local activities related to rural tourism in order to maximize local opportunities. On the basis of this result, residents should be advised to receive vocational, professional and entrepreneurial training as well as improve their knowledge about the rural tourism and local development.

Finally, both the administrative and human resources networks evidenced intermediate levels of centrality, which means that these types of interactions are not very intense among relevant stakeholders. This suggests that there is some rigidity in transference of this type of resources, which may partly be explained by a certain immobility of public administration entities. However, there are a number of actors that operate mainly in the nonprofit sector that could play an important buffering role. That is, although their major goals and resources may not be concerned with or designed for rural tourism and local development, they provide relevant services that contribute directly to the quality of the overall industry (Saxena \& Ilbery, 2008). For instance, colleges, schools and informal business groups/association can be viewed as important actors in providing locally based training.

\section{CONTRIBUTIONS FOR THEORY AND PRACTICE}

In terms of contributions of the study, the results have relevance for both theory and practice. From a theoretical stance, first, this study adopted an innovative methodology, SNA. As previously mentioned, the application of SNA is increasing in business relationships (Coviello, 2005; Scott et al., 2008) in the sense that the focus is shifting from dyads (relations between two actors) to triads (relations among subsets of actors). 
Second, this study brings a theoretical contribution to the strategic management by examining the stakeholders involved in tourism in a specific region, the PNPG. By analyzing and empirically testing the theory of Mitchell et al. (1997), the study proposes a typology of stakeholders based on three main attributes: power, legitimacy and urgency. The identification of different stakeholders' attributes, in the specific context of PNPG, provides a better perception of stakeholders' strategic behavior.

Third, this study draws insights from two key theories: stakeholder theory and network theory. The rationale behind this approach relates to the fact that stakeholders that have a greater control over resources within specific networks tend to occupy positions of greater prominence and greater responsibility.

Fourth, from a methodological perspective, the use of SNA has allowed not only the scrutiny of key stakeholders but also the identification of the structure of multiple interactions (marketing information, administrative resources, human resources, training and financial resources) of a specific tourism destination (Cooper et al., 2009).

From a practical perspective, it is expected that the cooperative activities undertaken among different local stakeholders to promote rural tourism and local development will generate enough funds not only for conservation of natural resources but also to contribute to build a brand that supports local business, to promote employment by triggering socially and culturally related activities and to improve visitor experiences. Also, the present study may assist local public policy-makers to design more appropriate policies and allocate resources to central actors.

\section{RESEARCH LIMITATIONS AND IMPLICATIONS FOR FURTHER RESEARCH}

The limitations and implications of the study are discussed in this section, and where applicable, some recommendations for further research are made. First, taking into account that this study is linked to the provision of tourism services, the characteristics that make services unique and different may also constitute an impediment in analyzing different relationships. Another limitation relates to the subjective nature of data. For instance, the different flows between stakeholders were measured on the basis of perceptions of respondents. Third, networks are dynamic constructs that change due to endogenous and exogenous factors. In line with Albrecht (2013), change can manifest itself in variations in the centrality of actors, in network density and other network characteristics. Therefore, these quantitative approaches are sometimes unsuitable to uncover these dynamics. Future research could also be developed by examining the level and quality of relationships as well as their dynamics. Finally, the sample used for analysis was drawn only from a specific Portuguese region, so the generalizability of the results to other regions remains to be tested.

\section{REFERENCES}

Albrecht JN. 2013. Networking for Sustainable Tourism - Towards a Research Agenda. Journal of Sustainable Tourism 21(5): 1-19.
Araújo L, Bramwell, B. 2002. Partnership and Regional Tourism in Brazil. Annals of Tourism Research 29(4): 1138-1164.

Attas D. 2004. A Moral Stakeholder Theory of the Firm. Zeitschrift für Wirtschafts - und Unternehmensethik 5(3): 312-316.

Baggio R, Scott N, Cooper C. 2010. Network Science - A Review Focused on Tourism. Annals of Tourism Research 37(3): 802-827.

Borgatti SP, Foster PC. 2003. The Network Paradigm in Organizational Research: A Review and Typology. Journal of Management 29(6): 991-1013.

Connelly G. 2007. Testing Governance-A Research Agenda for Exploring Urban Tourism Competitiveness Policy: The Case of Liverpool 1980-2000. Tourism Geographies 9(1): 84-114.

Cooper C, Scott N, Baggio, R. 2009. Network Position and Perceptions of Destination Stakeholder Importance. Anatolia 20(1): 33-45.

Cottrell S, Cutumisu N. 2006. Sustainable Tourism Development Strategy in WWW Pan Parks: Case of a Swedish and Romanian National Park. Scandinavian Journal of Hospitality and Tourism 6(2): $150-167$

Coviello NE. 2005. Integrating Qualitative and Quantitative Techniques in Networks Analysis. Quantitative Market Research: an International Journal 8(1): 39-60.

Del Chiappa, G, Presenza, A. 2013. The use of Network Analysis to Assess Relationships Among Stakeholders Within a Tourism Destination: An Empirical Investigation on Costa Smeralda-Gallura, Italy. Tourism Analysis 18(1): 1-13.

Driscoll C, Starik M. 2004. The Primordial Stakeholder: Advancing the Conceptual Consideration of Stakeholder Status for the Natural Environment. Journal of Business Ethics 49: 55-73.

Duhan DF, Johnson SD, Wilcox JB, Harrell GD. 1997. Influences on Consumer use of Word-of-mouth Recommendation Sources. Journal of the Academy of Marketing Science 25(4): 283-295.

Freeman RE. 1984. Strategic Management: A Stakeholder Approach. Pitman: Boston.

Frooman J. 1999. Stakeholder Influence Strategies. Academy of Management Journal 24(2): 191-205.

Getz D, Jamal T. 1994. The Environment-community Symbiosis: A Case for Collaborative Tourism Planning. Journal of Sustainable Tourism 2(3): 152-173.

Gnoth, J. 2003. Tourist activated networks: Towards a theory for destinations. Proceedings, 32nd EMAC, Thistle Hotel, Glasgow, Scotland, May 20-23.

Grabher G. 2006. Trading Routes, Bypasses, and Risky Intersections: Mapping the Travels of "Networks" Between Economic Sociology and Economic Geography. Progress in Human Geography 30(2): 163-189.

Halme M. 2001. Learning for Sustainable Development in Tourism Networks. Business Strategy and the Environment 10: 100-14.

Hardy AL, Beeton RJS. 2001. Sustainable Tourism or Maintainable Tourism: Managing Resources for More Than Average Outcomes. Journal of Sustainable Tourism 9(3): 168-192.

H-Y Shih. 2006. Network Characteristics of Drive Tourism Destinations: An Application of Network Analysis in Tourism. Tourism Management 27: 1029-1039.

Iacobucci D, Hopkins N. 1992. Modelling Dyadic Interactions and Networks in Marketing. Journal of Marketing Research 29(1): 5-17.

Iacobucci D, Ostrom A. 1996. Commercial and Interpersonal Relationships: Using the Structure of Interpersonal Relationships to Understand Individual to Individual, Individual-to-firm, and Firm-to-firm Relationships in Commerce. International Journal of Research in Marketing 13: 53-72.

Ioannides D. 2001. Sustainable development and shifting attitudes of tourism stakeholders: Toward a dynamic framework. In Tourism, Recreation and Sustainability: Linking Culture and the Environment, McCool SF, Moisey RN (eds). CABI Publishing: Oxon, OK.

Keeley M. 1978. A Contingency Framework for Performance Evaluation. Academy of Management Review 3(3): 428-439.

Kimbu A, Ngoasong, M. 2013. Centralised Decentralisation of Tourism Development: A Network Perspective. Annals of Tourism Research 40: 235-259. 
Laere van K, Heene A. 2003. Social Networks as a Source of Competitive Advantage for the Firm. Journal of Workplace Learning 15(6): 248-258.

Lemmetyinen A, Go F. 2009. The key Capabilities Required for Managing Tourism Business Networks. Tourism Management 30: $31-40$.

Leung X, Wang F, Wu B, Bai B, Stahura K, Xie Z. 2012. A Social Network Analysis of Overseas Tourism Movement Patterns in Beijing: The Impact of the Olympic Games. International Journal of Tourism Research 14(5): 469-484.

Lewis A. 2006. Stakeholder Informed Tourism Education: Voices from the Caribbean. Journal of Hospitality, Leisure, Sport and Tourism Education 5(2): 14-24.

Marzo-Navarro M, Pedraja-Iglesias M. 2012. Critical Factors of Wine Tourism: Incentives and Barriers from the Potential tourist's Perspective. International Journal of Contemporary Hospitality Management 24(2): 312-334.

Medlik S. 2003. Dictionary of Travel, Tourism and Hospitality. $3^{\text {rd }}$ ed., Butterworth Heinemann: Oxford.

Mitchell RK, Agle Bradley R, Wood DJ. 1997. Toward a Theory of Stakeholder Identification and Salience: Defining the Principle of Who and What Really Counts. Academy of Management Review 22(4): 853-886.

Morrison A, Lynch P, Johns N. 2004. International Tourism Networks. International Journal of Contemporary Hospitality Management 16(3): 197-202.

Morrison A, Thomas R. 1999. The Future of Small Firms in the Hospitality Industry. International Journal of Contemporary Hospitality Management 11(4): 148-154.

Murphy PE, Murphy AE. 2004. Strategic Management for Tourism Communities: Bridging the Gaps. Aspects of Tourism 16. Channel View Publications: Clevedon, UK

O’Donnell A, Gilmore A, Cummings D, Carson D. 2001. The Network Construct in Entrepreneurship Research: A Review and Critique. Management Decision 39(9): 749-760.

Pavlovich K. 2003. The Evolution and Transformation of a Tourism Destination Network: The Waitomo Caves, New Zealand. Tourism Management 24: 203-216.

Pearce JA. 1982. The Company Mission as a Strategic Tool. Sloan Management Review 23(3): 15-24.

Pesqueux Y, Damak-Ayadi S. 2005. Stakeholder Theory in Perspective. Corporate Governance 5(2): 5-21.

Pforr C. 2002. The 'Makers and Shakers' of Tourism Policy in the Northern Territory of Australia: A Policy Network Analysis of Actors and Their Relational Constellations. Journal of Hospitality and Tourism Management 9(2): 134-50.

Pforr C. 2006. Tourism policy in the making: an Australian network study. Annals of Tourism Research 33(1): 87-108.

Podolny JM, Page K. 1998. Network Forms of Organization. Annual Review of Sociology 24: 57-76.

Robson J, Robson I. 1996. From Shareholders to Stakeholders: Critical Issues for Tourism Marketers. Tourism Management 17(7): 533-540.
Rowley TJ. 1997. Moving Beyond Dyadic Ties: A Network Theory of Stakeholders Influences. The Academy of Management Review 22(4): 887-910.

Sautter ET, Leisen B. 1999. Managing Stakeholders: A Tourism Planning Model. Annals of Tourism Research 26: 312-328.

Saxena G. 2005. Relationships networks and the learning regions - case evidence from the Peak District National Park. Tourism Management 26: 277-289.

Saxena G, Ilbery, B. 2008. Integrate Rural Tourism: A Boarder Case Study. Annals of Tourism Research 35 (1): 233-254.

Schouten F. 1996. Tourism and cultural change. Proceedings of a round table: Culture tourism development. Crucial issues for the XXIst Century: Paris.

Scott J. 2000. Social Network Analysis: A Handbook. Sage: London.

Scott N, Cooper C. 2007. Network analysis as a research tool for understanding tourism destinations in development in tourism research. In Tribe J, Airey D (eds). Elsevier: Oxford, 199-215.

Scott N, Baggio R, Cooper C. 2008. Network Analysis and Tourism: From Theory to Practice. Channel View Publications: Clevedon.

Serrat O. 2009. Social Network Analysis. Asian Development Bank 28: $1-4$.

Sheehan L, Ritchie JRB. 1997. Financial Management in Tourism: A Destination Perspective. Tourism Economics 3(2): 93-118.

Slatter SS. 1980. Strategic Planning for Public Relations. Long Range Planning 13(3): 57-69.

Stokowski PA. 1992. Social Networks and Tourist Behavior. The American Behavioral Scientist (1986-1994), Nov/Dec, 36(2): 212-221.

Tichy N, Tushman M, Fombrun C. 1979. Social Network Analysis for Organizations. Academy of Management Review 4(4): 507-19.

Timur S, Getz D. 2008. A Network Perspective on Managing Stakeholders for Sustainable Urban Tourism. International Journal of Contemporary Hospitality Management 20(4): 445-461.

Timur S. 2005. A Network Perspective of Stakeholder Relationships in the Context of Sustainable Urban Tourism. Degree of Doctor of Philosophy, Haskayane School of Business: Calgary, Alberta.

Tinsley R, Lynch, P. 2001. Small Tourism Business Networks and Destination Development. Hospitality Management 20(4): 367-378.

Wanda G, Heather M, Donald R. 2009. Rural Tourism Development: Localism and Cultural Chgange. Channel View Publications.

Wasserman S, Faust K. 1994. Social Network Analysis Methods and Applications. Cambridge University Press: Cambridge MA.

Wearing S, Neil J. 1999. Ecotourism Impacts, Potentials and Possibilities. Butterworth-Heinmann: Melbourne.

Wood D, Gray, B. 1991. Toward a Comprehensive Theory of Collaboration. Journal of Applied Behavioral Science 27(2): 139-162.

Yuksel F, Bramwell B, Yuksel A. 1999. Stakeholder Interview and Tourism Planning at Pamukkale, Turkey. Tourism Management 20(3): 351-360.

Zsolnai L. 2006. Extended Stakeholder Theory. Society and Business Review 1(1): 37-44. 